\title{
Pricing of the Electricity Market for Household Customers in Bulgaria
}

\author{
PhD candidate Nevena Petrova \\ University of Economics - Varna, Varna, Bulgaria \\ nevadp@abv.bg
}

\begin{abstract}
This article aims to discuss electricity in the context of its pricing for household customers both in the regulated and the free markets. In the course of the theoretical review it is concluded that the mechanisms used in the pricing of the electricity market for household customers correspond to the law and that the electricity price should be as determined by the market, but at this stage the lack of maturity of the electricity market does not allow it to operate solely by market principles, which requires systemic regulation either through specialized legislation or through the intervention of a regulatory authority.
\end{abstract}

Keywords: electricity, electricity market, pricing

JEL Code: E3, L6; doi:10.36997/IJUSV-ESS/2019.8.1.18

\section{Въведение}

Ценообразуването на електрическата енергия се откроява със своята актуалност, продиктувана от динамиката в развитието на пазара на горива, законодателните промени, социалната политика и др., които пряко оказват влияние върху крайните параметри на търсенето и предлагането. Фокусът на вниманието ще бъде насочен главно към проучване на цялостните методики, които намират приложение на националния енергиен пазар, с оглед разкриване на техните структуроопределящи единици.

Целта на настоящата разработка е да бъде направен теоретичен обзор на ценообразуването на пазара на електрическа енергия за битови клиенти в България, диверсифициран на регулиран и свободен пазар и на тази основа да бъдат формулирани изводи, касаещи образуването на цените в енергийния сектор.

\section{1. Теоретичен обзор на ценообразуването на пазара на електрическа енергия за битови клиенти в България}

Методите за определяне цената на електроенергията са уредени в националното законодателство и намират приложение на функциониращия пазар на електрическа енергия, който се разделя на регулиран и на свободен пазар. При ценообразуването на електроенергията, освен икономическите показатели, се отчитат и редица социални, политически и други фактори, често пъти извън икономическата система. Определяща е констатацията, че в България все още е неадекватна ценовата рамка на регулирания пазарен сегмент, което затруднява и забавя развитието на свободния пазар (Grigorova, 2012). По този начин възможностите на свободния пазар на този етап са успели да привлекат едва 33 активни от общо регистрирани 44 пазарни участника в сегмента „Пазар в рамките на деня“ и 72 регистрирани пазарни участника в сегмент „Пазар ден напред“ към 31.01.2019 г. (IBEX, 2019) и 67 в сегмент „Централизиран пазар за двустранни договори“ (IBEX, 2019).

На регулирания пазар основните участници са битовите потребители и стопанските потребители на средно и ниско напрежение. Крайните цени на електрическата енергия за регулирания пазар се формират по веригата производство - пренос - разпределение снабдяване (вж. фиг. 1). При това ценообразуването преминава през няколко стьпки: първата стъпка при образуване на цените на електрическата енергия е извършването на технико-икономически анализ на ценовите елементи на производителите. Най-важният фактор, който оказва влияние върху цената на производителите, е стойността на използваното основно гориво за производство (вьглища, природен газ и др.). Анализират се ежегодно и нивата на постоянните разходи на отделните централи, като се извършва 
преценка за обоснованост на представените искания от производителите. Втората стыпка е определянето на т. нар. „квоти” за количествата електрическа енергия, необходими за осигуряване на потреблението на регулирания пазар.

Производителите на електрическа енергия съгласуват с Електроенергийния системен оператор (ЕСО) производството на електрическа енергия за

съответната ценова година и подават своите заявления за цени в Комисия за енергийно и водно регулиране (КЕВР)

„НЕК” ЕАД, като Обществен доставчик (ОД), подава заявление с договорените количества енергия от АЕЦ „Козлодуй“, ТЕЦ, които формират голяма част от енергията необходима за регулирания пазар

Останалата част от енергията се осигурява от „НЕК” ЕАД съгласно законовото

задължение да изкупува задължително енергията по дългосрочни договори, възобновяеми енергийни източници, топлофикационни и заводски централи по преференциални цени

Формиране на цена на енергията за регулирания пазар с включени административни разходи на Обществения доставчик

Фигура 1. Определяне на „миксовата“ цена на електрическата енергия

Квотите за производителите се определят въз основа на приета от Комисия за енергийно и водно регулиране (КЕВР) методика.

Количествата енергия, необходими за гарантиране на потреблението на регулирания пазар, се осигуряват както от единствената в страната атомна централа и кондензационните централи, така и от енергия, закупена по дългосрочни договори с производители от възобновяеми енергийни източници (ВЕИ), енергия от комбинирано производство, от топлофикационни и заводски централи.

След определяне на квотите за регулирания пазар, на база индивидуалните регулирани цени на производителите, се изчислява средната цена на електроенергията, по която „НЕК” ЕАД продава на електроразпределителните дружества и крайните снабдители. Към тази средна цена, наричана още цена от „микса” за регулирания пазар, се добавя „надбавка” (постоянни разходи и възвръщаемост) за „НЕК” ЕАД в качеството му на Обществен доставчик.

Следваща стьпка от ценообразуването е извършването на анализ и оценка на елементите, формиращи цените за „пренос през преносната мрежа”, „достъп до преносната мрежа". Също така се извършва и анализ и оценка на разходите за произвежданата енергия от ВЕИ, високоефективно комбинирано производство и енергията, произвеждана от кондензационни централи по сключени дългосрочни договори, формиращи съответно добавките за: „зелена енергия”, „високоефективно производство“ и „невъзстановяеми разходи“. Тези три добавки представляват разходи за енергия и са определени като отделни елементи на крайната продажна цена, с оглед справедливото им заплащане от всички потребители както на регулирания, така и на свободния пазар.

По същество цената за достып до електропреносната мрежа включва над 90\% разходи за студен резерв, които системният оператор заплаща на кондензационните централи, с 
оглед управлението на електроенергийната система и осигуряване на непрекъснато снабдяване с електрическа енергия на всички потребители, в случай на непредвидени ситуации в някоя от основните мощности. В своята обща форма енергийната система е съвкупност от електроцентрали (генериращи, трансформиращи, предаващи, акумулиращи, консумиращи), свързани помежду си чрез енергийни и икономически връзки по такъв начин, че условията на работа на тези централи си оказват взаимно влияние (Loktionov, 2013), (Loktionov, 2015) и изискват „приспособяване“ на енергийната система към променящи се външни и вътрешни условия за постигане на първоначално поставената цел и за новоформулирани задачи (Loktionov, 2016).

Добавката за „зелена енергия“ се образува по методика, одобрена от КЕВР, заплаща се от всички потребители и се превежда от електроразпределителните дружества към „НЕК” ЕАД. Тя представлява стойността на екологично чистата енергия от възобновяеми енергийни източници (ВЕИ), като целта е стимулиране развитието на производството от възобновяеми енергийни източници, съгласно изискванията на Европейските директиви (с източници от вятърни централи, фотоволтаични централи, ВЕЦ до 10 МВт и др.). По този начин всички потребители, присъединени към електропреносната и електроразпределителната мрежа, заплащат за произвежданата екологична енергия в България.

Добавката за „високо-ефективно комбинирано производство“ се образува по методика, определена от КЕВР, заплаща се от всички потребители и се превежда от електроразпределителните дружества към „НЕК“ ЕАД. Това са част от разходите за производство на енергия, произведена от инсталации за високо ефективно производство, чрез прилагане на комбиниран способ за производство на електрическа и топлинна енергия.

Добавката за „невъзстановяеми разходи”, въведена от 01.07 .2012 г., когато българският електроенергиен пазар е напълно либерализиран. Тя е свързана със съществуващите законови изисквания в Закона за енергетиката (Zakon za energetikata, 2019), където в чл. 34, ал. 2 се посочва, че като „невъзстановяеми разходи“ са класифицирани онези, произтичащи от извършени инвестиции и/или сключени сделки до влизането в сила на Закона за енергетиката от енергийните предприятия, които не могат да бъдат възстановени в резултат на създаване на конкурентен електроенергиен пазар, във връзка с поетите задължения по дългосрочни договори. За новия регулаторен период се извършва оценка на разходите за енергия, произвеждана от централите по дългосрочни договори. Тази добавка е изчислена като разлика между пълните разходи за производство и разходите за производство по „базисна цена“, представляваща средна цена на енергията, произвеждана от кондензационни централи и ВЕЦ над 10 МВт (вж. фиг. 2).

Последната стыпка от ценообразуването на електроенергията е формирането на стойността на мрежовите услуги на електроразпределителните дружества и тарифите на крайните снабдители. Тези мрежови услуги са свързани с експлоатацията и поддръжката на разпределителната мрежа и се финансират от цената за разпределение, съответно за средно и ниско напрежение. Разделянето на мрежовите услуги на електроразпределителните дружества на цена за достъп и цена за пренос, за съответното ниво на напрежение, има за цел диференцирането на постоянните разходи, свързани с експлоатацията на мрежата между отделните групи потребители. Определянето на двукомпонентна цена на мрежовите услуги, подлежащи на ценово регулиране по Закона за енергетиката, е мотивирано от принципа за „справедливи цени”, тоест всеки клиент да заплаща разходите, които сам предизвиква. В случай, че се използва еднокомпонентна тарифа всички разходи се заплащат чрез консумираната електроенергия. Разходите по поддържане на съоръженията за клиенти, които не са консумирали или са консумирали значително по-малко от заявените количества, се заплаща от останалите клиенти.

Крайната цена за електроенергия, плащана от крайните потребители, се формира на база горепосочените разходи и е илюстрирана на фигура 3. 


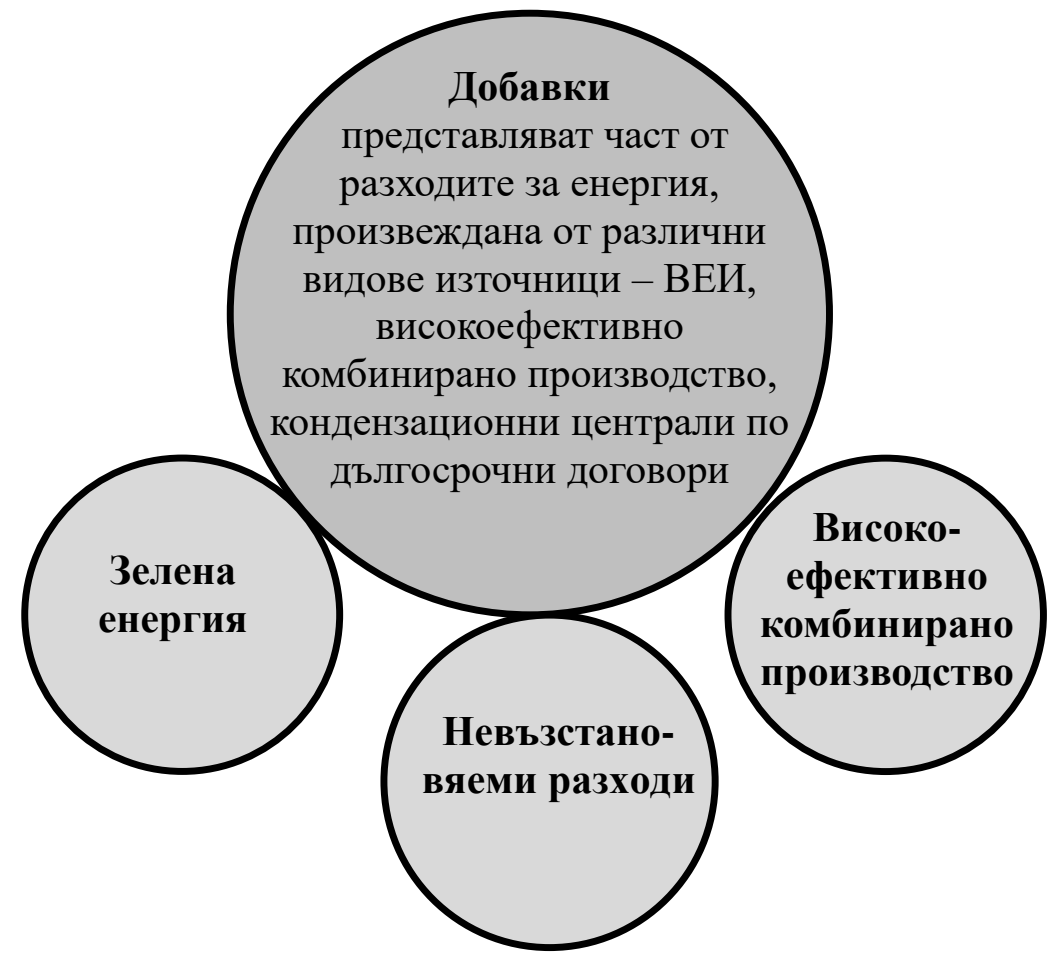

Фигура 2. Добавки към цената за пренос

Формирането на крайната цена, включваща всички разходи, свързани с производството и доставката на енергия, е както следва:

- приблизително 65 \% от крайната цена са разходите за енергия;

- останалите $35 \%$ са разходи за мрежови услуги.

От съществен интерес на потребителите е наличието на ефикасен контрол върху разходите на регулираните предприятия от страна на контролната институция, защото това оказва пряко въздействие върху цените на електрическата енергия. Но въвеждането на методи за регулиране със стимули за ефективност влияе по-силно и по-дългосрочно върху снижаването на ценовите равнища и до голяма степен намалява нуждата от администриране и регулаторен контрол.

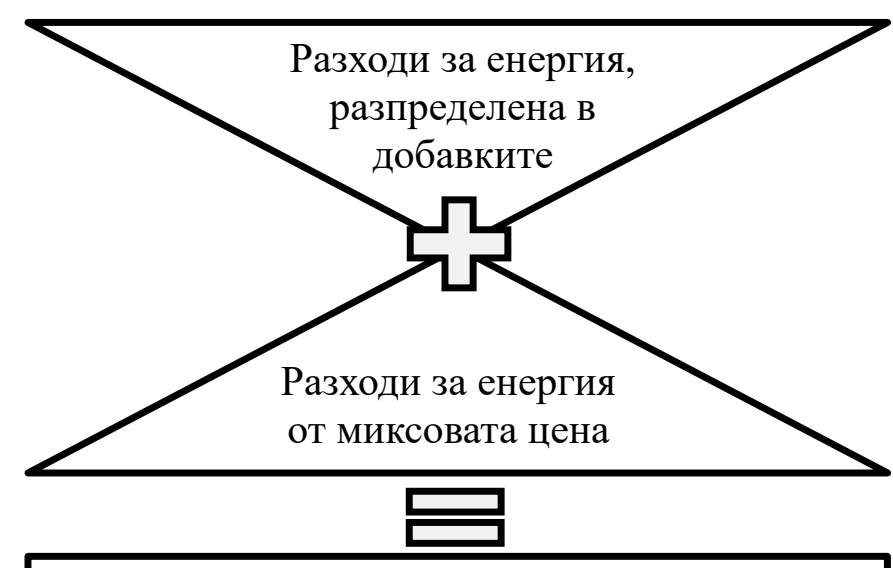

Пълна цена

за енергия, която плаща крайния потребител

Фигура 3. Общи разходи за енергия (KEVR, 2019) 
Най-простият за администриране метод за ценово регулиране е „Горна граница на приходите”. След определяне на приходи за определен базисен период и целеви показатели, които трябва да се постигнат през регулаторния период (първият период след приемане на нормативната уредба е тригодишен, а последващите са петгодишни), ежегодно би трябвало да се прилага само формула за индексация. Същото се отнася и за повечето случаи на прилагане на метода „Горна граница на цените”. При тези методи енергийните дружества са мотивирани да работят по-ефективно, тъй като имат възможността да реализират допълнителна възвръщаемост, ако „преизпълнят” целевите показатели, зададени от регулатора. От своя страна, това се отразява като ефект за потребителите при определяне на горната граница на приходите/цените за следващия регулаторен период, по този начин поради постигнатата по-висока ефективност, необходимите ценови равнища ще са по-ниски.

Ключовите трудности при прилагането на тези системи са при избора на подходящи показатели за ефективност и качество, и при определянето на техните точни параметри. За случая на електроразпределителните дружества, например, определянето на целевите показатели за намаляване на технологичните загуби и на целевите показатели за качество за определен период от време изисква реалистична преценка на технологичните срокове и прецизна оценка на необходимите инвестиции за постигането им. По-кратките срокове и повисоките цели изискват и по-големи ежегодни инвестиции, а съответно и по-високи ценови нива. Постигането на баланса между изискванията за по-висока ефективност и качество и разумните ценови повишения би трябвало да бъде основната задача на регулатора при равни други условия.

В момента на регулирания пазар цените се определят веднъж годишно, прието е това да бъде реализирано през месец юли на текущата година. Затова потребителите биват уведомяват един път годишно, каква е новата тарифа, по която ще се калкулират сметките за електроенергия.

Новото европейско законодателство налага либерализирането на електроенергийния пазар и основната цел на тази трансформация е въвеждането на свободна конкуренция между участниците на пазара. Неговото функциониране е основна предпоставка за балансиране на производството и реализиране на по-ниски разходи на електроенергия от потребителите, а също така е в основата на повишаването на качеството на предлаганите услуги и надеждността на снабдяването.

На свободния пазар клиентите могат да договарят цената на електрическата енергия с избраните от тях доставчици, тоест свободният пазар дава възможност на клиентите от една страна да избират своя доставчик на енергия, който е селектиран по определи критерии лицензиран търговец, а от друга да договарят нейната цена на база подадени почасови прогнозни количества. Това позволява от една страна адаптиране в съответствие със собствените потребности, съобразяване с пазарната конюнктура и най-вече оптимизиране на използвания ресурс, посредством прилагане на икономически формулирана инвестиционна стратегия.

Характерно за либерализирания пазар е, че на договаряне подлежи единствено цената на електрическа енергия. Отделно обект на договаряне може да бъде и цената на всяка отделна тарифа, срокове и начини на плащане, продукти, профили, обслужване и др.

Цените за мрежовите услуги, тоест цените за достьп до и пренос през електропреносната и електроразпределителната мрежа, се определят от КЕВР, дължат се от всички клиенти и не подлежат на договаряне. Последното не означава, че зад тяхното определяне няма икономическа аргументация и прилагане на пазарната концепция, но като цяло протича в един условно по-слабо информационно оповестен за обществото режим.

Клиентите на свободния пазар на електрическа енергия заплащат и цена за „задължения 
към обществото“, определена от КЕВР и с нея се компенсират разходи, свързани с дългосрочните договори за гарантирано изкупуване и закупуването на електрическа енергия от ВЕИ производители по преференциални цени. Последното отново е израз на външна намеса в пазарната среда и принципи, което от една страна се аргументира с необходимостта за ускорено възстановяване на инвестициите в тези ресурсоемки енергийни проекти, но основно е израз на поетите ангажименти за достигане на определено ниво на електрическата енергия с произход ВЕИ в националния енергиен микс.

На свободния пазар на клиента е дадена гаранция, че ще плаща една и съща цена за енергия по време на цялата продължителност на неговия договор. Следователно, ако клиентът е сключил договор за една година с определена фиксирана цена с доставчик на свободен пазар, то той ще знае с точност каква цена за единица енергия ще трябва да заплаща по време на целия договорен срок. Доставчикът не може по свое усмотрение и едностранно да променя договорената за периода цена. По този начин се създава краткосрочна стабилност за бизнеса по отношение цената на енергията, която е на равнище, определено в постигната договореност и позволява същата да не влияе в посока на увеличение на крайната цена на създаваните продукти при равни други условия.

Свободният пазар предлага по-голям брой предимства за стопанските клиенти, отколкото регулирания пазар, но в същото време крие и известни рискове. Най-същественото e, че потребителите могат да бъдат привлечени с ниски ценови равнища, а същевременно да има скрити условия в договора и неособено добронамерени търговски практики и договорни неустойки. Едновременно с това в определени ситуации, поради умишлени или без изяснен произход причини, може да бъде нарушено функционирането на конкурентния пазарен механизъм, което да доведе до изкривяване на пазара. Произходът на подобни състояния е обусловен от ниската пазарна ликвидност, моментните пикове или спадове в търсенето и предлагането на вътрешния пазар, влиянието на характеристиките на международния пазар, поведението на определени пазарни участници и др. Общото зад подобно пазарно състояние е редуцирането на информационния поток от и към пазара, както и липсата на достатъчно познание, придържането към определен кодекс за справедлива бизнес етика и лоялно поведение на пазарните участници.

Що се отнася до битовите потребители, свободният пазар за тях не е особено атрактивен към момента, защото до настоящето не е регистриран случай, в който цената на свободния пазар да е била по-изгодна от тази, определяна от енергийния регулатор. Допълнителни пречки са консервативното поведение на битовите потребителите по отношение на доставката на този стратегически ресурс и възможностите за ефективно прилагане на инструментите за защита на потребителите.

В обобщение може да се каже, че на либерализирания пазар:

- Ц Цената се определя от двустранни договори.

- Съществува възможността за индивидуално-определен микс от източници.

- В Взможности за планиране на потреблението “ден напред”.

- Поемане на допълнителна отговорност и разходи за балансиране.

- Предлагане на сложен комплекс от допълнителни енергийни услуги.

- $\quad$ Различен подход за формиране на разходите, изразен като: Разходи = Енергия + Мрежа + Балансираща енергия (вж. фиг. 4).

В сравнителен план могат да бъдат разгледани основните характеристики на регулиран и либерализиран пазар (вж. фиг. 5 и 6).

На регулирания пазар цената се определя административно от КЕВР и клиентите могат да закупуват енергия само от един лицензиран доставчик, а свободният пазар дава възможност на потребителите да сключват сделки по договорени цени между производители, търговци и крайни клиенти, както и възможност за избор на един или няколко доставчици на електроенергия. 


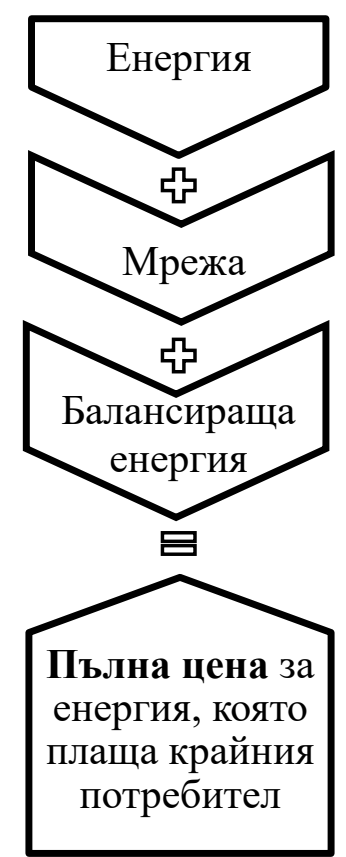

Фигура 4. Разходи за енергия на свободен пазар

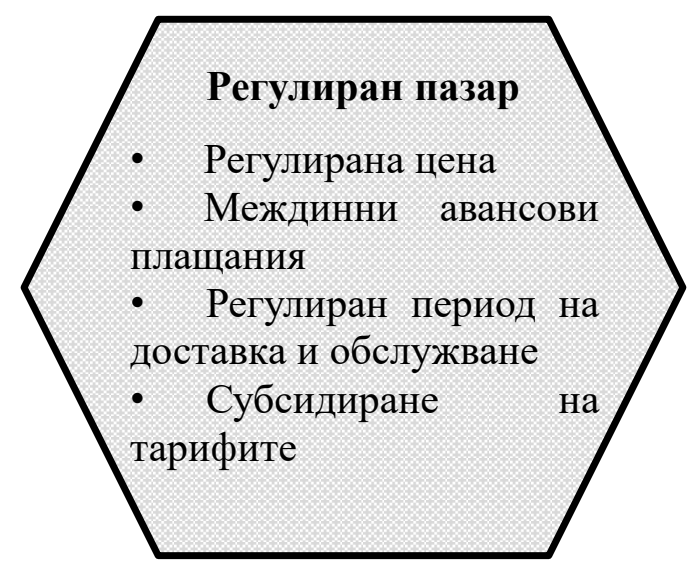

Фигура 5. Характеристики на регулиран пазар

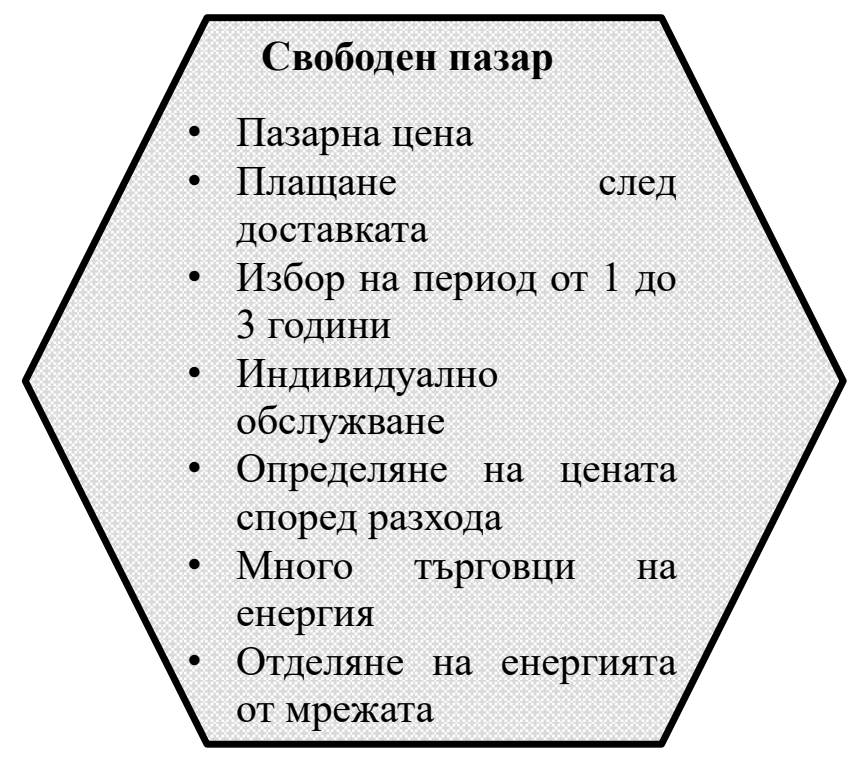

Фигура 6. Характеристики на свободен пазар 
За разлика от регулирания пазар, където търговията се осъществява след като е направена доставката, на свободния пазар търговията се извършва преди момента на доставката, което означава, че се правят предварителни прогнози и разчети на очакваното потребление за всеки час, а също така и балансиране, с оглед на минимизиране на разликата между прогнозното и реално отчетеното потребление. Към всеки клиент търговците на свободния пазар имат специално отношение и се стараят неговите нужди да бъдат обслужени изцяло. Не се налага клиентът да губи време в чакане на отговор на телефонен оператор и на опашка в клиентски центьр, търговецът сам отива при клиента, когато е необходимо. От друга страна обаче на регулирания пазар клиентите са запознати с условията и действащите правила, а на свободния пазар се сблъскват с неумението си да оценят предимствата и рисковете при различните оферти, защото на свободния пазар на електроенергия конкуренцията не е само в цената на електроенергията, а и в условията за доставката, начина на плащане на сметките, развитието на енергийните услуги, предлагани в допълнение от доставчиците. Всичко това означава, че на свободния пазар клиентите могат предварително да договорят условията на тьрговската размяна, което е нормалният пазарен процес, докато на регулирания пазар условията са нормативно определени и зададени за всички пазарни участници, което може да бъде в някои ситуации и за някои агенти преимущество, докато за други да бъде недостатък, особено в сравнителен план с условията на размяната на свободния пазар.

Ценообразуването на регулирания и на свободния пазара преследват баланс и постигане на определени икономически и социални цели както за отделния потребител, така и за всички останали пазарни участници. На този етап липсата на зрялост на пазара на електрическа енергия не позволява той да бъде управляван единствено от пазарни принципи, което налага системната регулация посредством въвеждането на специализирано законодателство и/или чрез намесата на регулативен орган. Дали в близкото бъдеще ще се премине към изцяло либерализиран модел, ще покаже само времето и готовността на икономическите агенти да се включат пълноценно като „свободни“ участници на пазара на електрическа енергия.

Изводи от направения теоретичен преглед на ценообразуването на енергийния пазар в страната:

1. Механизмите, използвани при ценообразуването на пазара на електрическа енергия за битови клиенти кореспондират с нормите на закона, залегнали в правната рамка на държавата, която е израз на националния суверенитет.

2. Цялата нормативна уредба, необходима за либерализацията на електроенергийния пазар е налична и стъпките в посока на либерализацията на пазара и гарантиране на енергийната независимост са стратегически зададени.

3. Цената на електроенергията трябва да бъде такава, каквато я определя пазарът, като в същото време е необходимо разделяне на пазарния от социалният елемент в ценообразуването, тоест цените да са пазарни, а държавата трябва да поеме своята социална отговорност и водеща роля по отношение на „енергийната бедност“.

\section{Заключение}

Ценообразуването на електрическата енергия като стратегически ресурс е с огромно национално значение и поради това е обект на специфично законодателство и държавно регулиране. Българският енергиен пазар е разделен на регулиран и свободен пазар, което определя и методите на ценообразуване. На регулирания пазар крайните цените се формират 
по веригата „производство - пренос - разпределение - снабдяване“. На свободния пазар действат ценови механизми, определени от търсенето и предлагането, тоест функционирането на принципите на свободния пазарен механизъм. В допълнение този пазарен сегмент гарантира по-широки възможности за индивидуален подход на обслужване на клиентите.

\section{Използвана литература / References}

1. Grigorova, V. (2012) Regulirane i liberalizatsiya na energï̌niya pazar $v$ Bulgariya. // Ikonomika i upravlenie, god. VIII, № 2, s. 6.

2. IBEX (2019), Sredni tseni na dnevna baza Yanuari 2019 g. Sofiya. Dostupen na: <http://www.ibex.bg/d.php?id=900> (23.09.2019).

3. IBEX (2019) Uchastnitsi. Sofiya, 2019. Dostupen na: <http://www.ibex.bg/bg/chlenstvo/uchastnitsi-21> (23.09.2019).

4. Loktionov, V. I. (2013) Svoystvo adaptivnosti kak kriteriy effektivnosti investitsionnykh proyektov v toplivnoenergeticheskom komplekse. // Ekonomicheskiy analiz: teoriya i praktik, 2013, № 6, s. 46-50.

5. Loktionov, V. I. (2015) Adaptivnost variantov razvitiya energeticheskikh sistem kak pokazatel energeticheskoy bezopasnosti. // Ekonomicheskiy analiz: teoriya i praktika, № 40, s. 11-21.

6. Loktionov, V. I. (2016) Vliyaniye investitsionnykh proyektov na uroven adaptivnosti energeticheskikh sistem $\mathrm{v}$ zadachakh dolgosrochnogo prognozirovaniya rynochnogo sprosa na energonositeli. // Ekonomicheskiy analiz: teoriya i praktika, № 4, s. 46-56.

7. Zakon za energetikata. Obn. DV. br. 107 ot 9 Dekemvri 2003 g., izm. i dop. DV. br. 41 ot 21 Mai 2019 g. Dostupen na: <https://lex.bg/bg/laws/ldoc/2135475623> (17.09.2019).

8. KEVR, Kak se obrazuva tsenata na toka? Dostupen na:<http://www.dker.bg/NPDOCS/prices_el.pdf> (27.09.2019). 